\title{
Research and Application on Technical Implementation Architecture in University Informatization Planning
}

\author{
Hong Lin, Yajuan Sun \\ Network and Information Center \\ North China Electric Power University \\ Beijing, China \\ syj@ncepu.edu.cn
}

\begin{abstract}
This article conducts the research on university informatization architecture by the idea learning from of enterprise architecture (EA), and discusses the importance of the technical implementation in the university informatization, describes the design methods and process in detail for the technical implementation architecture, for which given the best practices model.
\end{abstract} Keywords- Information resources planning;Enterprise
Architecture;University architecture

\section{INTRODUCTION}

It is not a direct transition from the phase of informatization development planning to the implementation in university informatization construction, a middle link is necessary which is the university information resources planning. Information Resource Planning is a continuation and refinement of the informatization development plan, also the premise and basis of the informatization implementation, and a bridge between the informatization planning and implementation which plays a connecting role. The main work about university information resources planning includes[1]: establish university business model by combing and optimizing core business processes; establish university data requirement model by the data requirement analysis based on the user view; establish function model, data model and architecture model of university-level information system and complete the overall strategic data planning according to business model and data requirement model. The results of information resources planning solve the data shared problem of a university information system, eliminating information islands resulted from self-creating and self-using of information systems, the next work to be done, is how to build informatization implementation architecture to realize the scientific and effective implementation for the planning results, and form the university informatization architecture composed by information resource planning and technical implementation.

II. THE CONNOTATION OF TECHNICAL IMPLEMENTATION ARCHITECTURE FOR UNIVERSITY INFORMATIZATION

University Architecture(UA), also known as university informatization architecture, borrowed the idea of the Enterprise Architecture (EA), survey the interaction relationship with the business, information, technology and application corresponding to informatization from the global

\author{
Baohui Wang \\ School of Software \\ Beijing University of Aeronautics and Astronautics \\ Beijing, China \\ wangbh@ncepu.edu.cn
}

perspective of the university, describes the overall structure of the university informatization using structured architecture and hierarchical framework method[2]. University architecture is shown in Fig. 1.

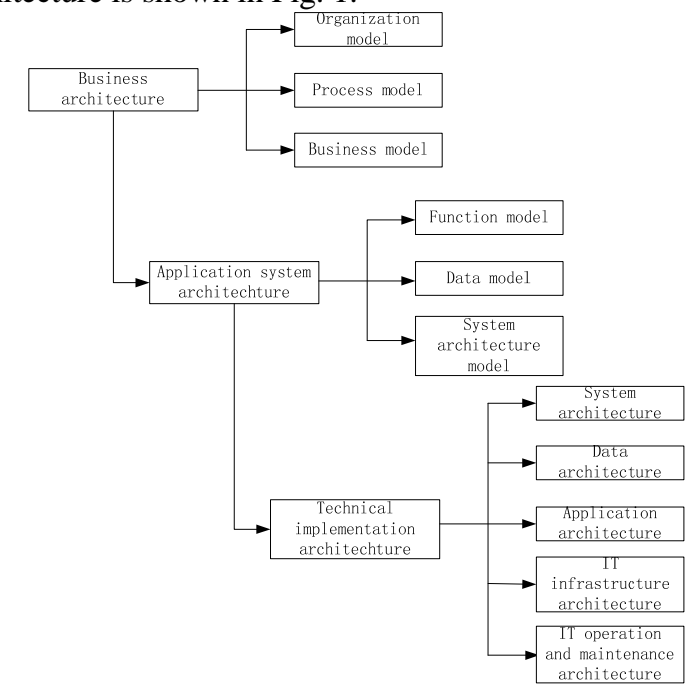

Figure 1. university informatization architecture model

University informatization architecture provides the theoretical basis for the top-level design of informatization, directly guides the university informatization construction. Among them, the business architecture and information system architecture completed at the university information resources planning stage solve the problem of "how to do" of informatization, while the problem of "how to land" of the model should be solved in the design stage of the technical implementation. Technical implementation architecture involves the five aspects of the system architecture, data architecture, application architecture, IT infrastructure, IT operation and maintenance architecture, of which results make the top-level design model targeted, the university informatization work more operational in the implementation process, and change the situation that all the schools are the same, or no actual effect is producing in spite of spending money. 


\section{THE APPLICATION OF TECHNICAL IMPLEMENTATION ARCHITECTURE FOR UNIVERSITY}

\section{A. Application System Architecture}

Application system uses a three-layer architecture, the display logic(interface) is separated from the business application logic into the presentation layer, business logic layer and data access layer for distributed information processing system to further improve the performance.

The presentation layer is located at the top layer, to provide the interacted interface for users with the application systems, responding for receiving user input data and displaying results handled by the business logic layer to the user. The presentation layer only completes to receive and display the data, excluding the code relevant to the data access and business processing logic.

The business logic layer plays the connecting role between the presentation layer and data access layer, responsible for the incoming data validation of the presentation layer, realization of the system business processes and access or storage of the data in database.

Data access layer is sometimes referred to as the persistence layer, and its main function is responsible for access to the database, and encapsulating a SQL statement or stored procedure, which can access the database system, binary file, text document or an XML document , with no business logic or interface-related code, nor any business data processing.

The non-functional requirements of the application system should be fully considered in the deployment of the three-layer architecture system, as is shown in Fig. 2, threelayer structure is corresponding to the web service layer, application service layer and data service layer, each layer can be composed by several servers.

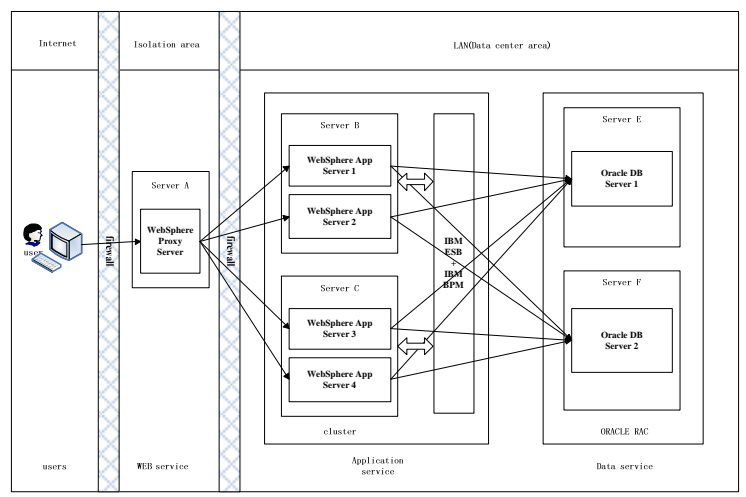

Figure 2. deployment model for the three-layer architecture system

Use a firewall to isolate the web layer to ensure the security of the application and data layers. The deployment solution that the application services and data services are deployed using distributed servers cluster has functions of load balance, redundancy, hot backup, which is for the core business systems in university such as undergraduate or graduate management system with large number of concurrent users and huge average volume of the business.
By load balance technology, we can use multiple servers to provide application and data services as well as a large number of users, breaking through the restrictions of providing service for only limited users on one server. When a server fails, the load balancing server will automatically detect and stop the service requests being distributed to the server, continue to provide services by other working servers, to ensure the reliability of services.

\section{B. Data Architecture}

The data architecture is to address the data shared and integrating issues between various application systems within the university, on the one hand, to consider the deployment of shared database of the new system, where shared database should be the subject database according to strategic data planning [3]; also to provide solution for old system data integration, as is shown in Fig. 3.

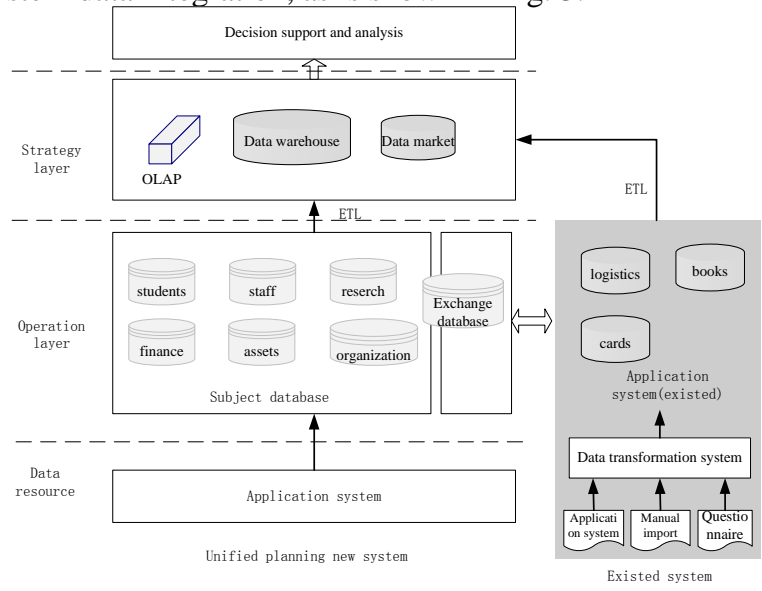

Figure 3. data architecture model

The data in operation layer are online transaction processing (OLTP) data, which are the basic, daily transaction processing system application in the university, such as undergraduate management systems, human resources management system, etc... The databases of the operation layer are the unified planning subject databases. Operation layer data from the university business systems are input once and on one place, to ensure its accuracy, timeliness and integrity which are shared database created and used together for various application systems.

The data in strategy layer is online analytical processing (OLAP) data, which are main applications for data mart and data warehouse, supporting for complex analysis operations, focusing on decision support, and providing intuitive query results. The data in the operation layer loaded into the data mart and data warehouse by ETL tools for cleaning, converting, integrating, have become the online analytical processing and data mining basis.

\section{C. university-level information system architecture}

University-level information system architecture is to solve application integration problems, composed by the data service layer, business service layer, integration service layer, integration application layer, as is shown in Fig. 4. 


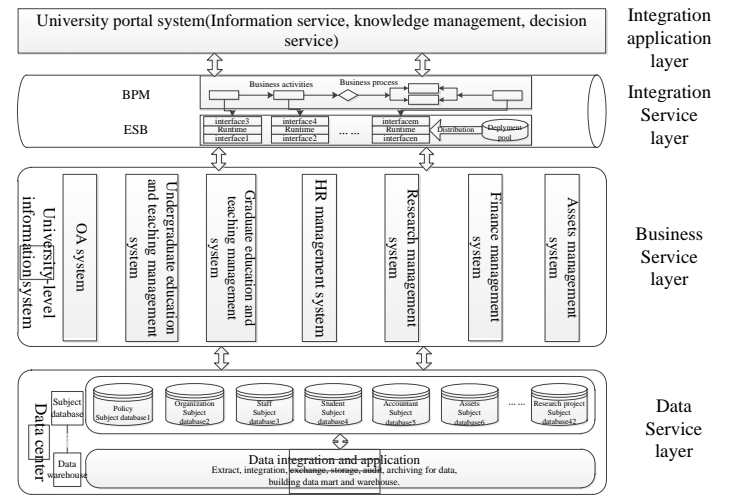

Figure 4. university-level information system architecture model

The data service layer is the data architecture described above. Business service layer is the principal of the university informatization, supporting the main business of the university, including office automation system, undergraduate management system, graduate management system, human resources management system, scientific research management system, financial management system and asset management system, etc..

Integration service layer consists of the components of the enterprise service bus (ESB), business process management (BPM) and service control, to achieve transparent access and linkage by the application systems integration services through the enterprise service bus cascade and unified control for the service catalog and service library in the application systems. Interaction between the application systems is accomplished by integration services to avoid the construction of the directattached channel interface between systems and to strengthen the unified management of the subsystem integration through a unified and integrated specification. Meanwhile, the integration service layer has multi-language, multi-protocol, cross platform capabilities. Business Process Management (BPM) is the core components of the integrated services, where the synergy of cross-application business processes is achieved, and the business process flowing between various application systems does with the integration services.

Integration application layer is the university portal system above a variety of applications, to show the information of all kinds of university information applications for users through the browser, which integrates the gaps between all kinds of applications, making the school users (teachers, students, workers, school personnel, etc.) freely custom personalized information. University portal system complete all the features of the portal site itself, to provide access to various services, such as decision support system, office automation system, research management system, financial system and so on. Business applications need to be registered and available to users in the portal. The information processing of the university portal system is divided into four parts: information access, unified management, authorization, display.

\section{IT Infrastructure}

IT infrastructure is the basis of supporting the university informatization implementation, including network infrastructure, network security system, data center, as shown in Fig. 5.

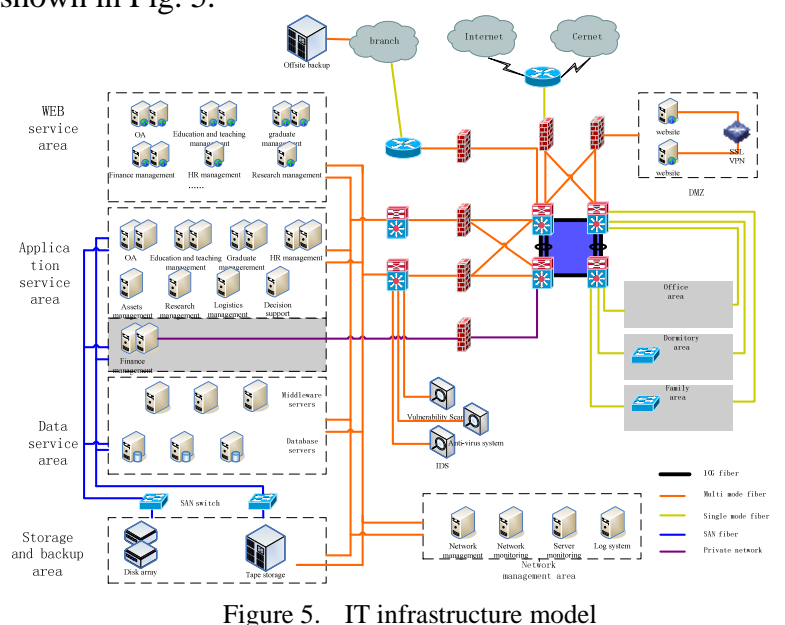

The design principles of network infrastructure need to consider the following four points: 1) Reliability. The critical links and equipment should be redundant, such as the core layer composed of a fiber optic ring network to avoid single point failure, to ensure the provision of uninterrupted service; 2) Security. The important information should have transport security measures, such as VPN for off-campus access to university information systems, control and quarantine measures on the access to the private network and data ,for example, deploying firewall on the keys areas; 3) Maintainability. The network structure should be clear and reasonable, easily to extend and maintain, such as three-layer structure of the campus network; 4) Advancement. It is able to support the expansion of the new network business, such as supporting distributed IPV6 technology for doing the technical preparations for the next generation Internet applications.

The network security system is related to the seven areas: a) To deploy firewall in the campus network and the servers area against attacks from outside as well as office network. According to the business district in the data center, more than one firewall should be deployed to achieve different levels of security and defense; b) To deploy a web firewall in front of the web server, to protect web servers and avoid web page being maliciously altered; c) To deploy the intrusion detection and defense system, to enhance the security warning and blocking capabilities for the outlet and server area, and enhance their ability to guard against external network defense; d) To deploy anti-virus gateway in the key areas as data center, to enhance the anti-virus capacity of the servers; e) To deploy the SSL VPN, to achieve secure access to private network resources from the social users; f) To deploy the off-site disaster recovery system, to ensure the fast recovery of business through offsite backup of business data when unexpected disaster occurs; g) respectively, To deploy the network monitoring and server monitoring system 
for monitoring the operation circumstance and performance of network, server and a variety of applications, databases, performance monitoring, to achieve timely detection the failures and anomalies and proactive defense.

Data center is the master control center for data and business applications. Data center constructions must be for the development of the university business, and provide a full range of business support for the university. This support covers all of users, university business, university data and decision support, therefore, the data center is the "heart" of the university informatization, with the important consideration of the planning and design for the servers cluster and data backup and disaster recovery. Three-layer logical structure of application systems, namely, the presentation layer, the business logic layer, the data access layer, are corresponding to the web service area, application service area, data service area in the data center. The equipments selected are mainly the blade servers in the web service area, the PC servers in the application service area and the minicomputer in the data service area. According to the needs of university-level information systems architecture, middleware like ESB or BPM is deployed in the data area. Data backup should be the unified network storage for the university with high-performance, versatile, high stability, and the integrated network storage platform with the optical storage, NAS storage, iSCSI storage. Data disaster recovery system should be the network backup and recovery system composed by the backup server, backup storage devices, backup software, backup clients and network access equipment.

\section{E. IT operation and maintenance architecture}

With constant improvement of the university informatization construction, and the expansion of the scale of the information systems, the business becomes increasingly dependent on the system. Because the system has become more complex, and the system maintenance demand has become increasingly higher, IT service management concept to be introduced is necessary, to achieve the accurate operation and maintenance, the comprehensive and centralized management of information systems. The operation and maintenance services will be built on the basis of standardization, low-cost and low risk, to realize the transformation of IT operation and maintenance services of the university from the passive mode to the streamline management. IT service processes need the organizational structure corresponding to the IT operation and maintenance services, to break the present university department system, combined with IT service management strategy and organizational structure. IT operation and maintenance system can be designed as the "third line" [4], process-oriented service architecture, as is shown in Fig. 6.

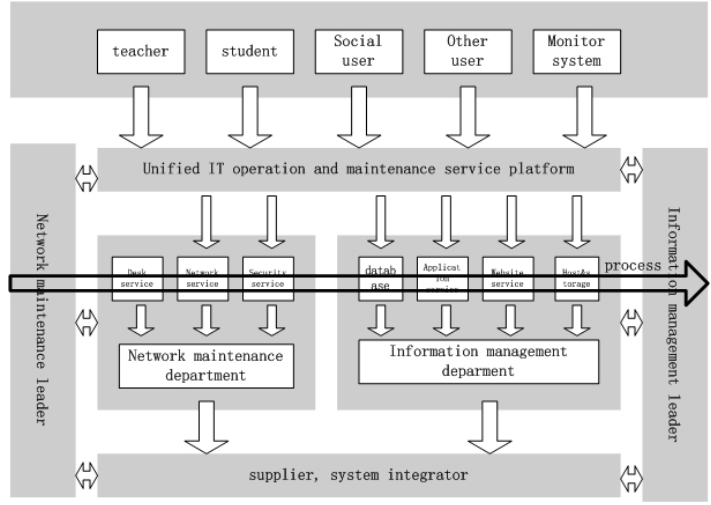

Figure 6. IT operation and maintenance structure

Front-line services are provided by service desk, secondline services by the technical staff in the information center, third-line services by the IT service provider. The horizontal, we make the corresponding departments of the information center match the IT service architecture, breaking down the traditional separation of business, establishing the IT operation and maintenance process systems with information center characteristics. The vertical, we build the "third line" level of IT services, and provide support for IT operation and maintenance service.

\section{CONCULSION}

The goal of university informatization is the full realization of educational informatization, management informatization and service informatization. In the informatization process from planning to implementation, not only we need the scientific methodology, but also effective technical support, make informatization work really paid off. In informatization planning, the technology implementation framework is a key aspect of which informatization goals can be achieved and also easy to overlook the point in the actual work, our employees continue to study and explore in practice, to make informatization work's effectiveness really be seen in the university, thereby enhancing the core competitiveness of the whole university.

\section{REFERENCES}

[1] F.X. Gao, "Information Resource Planning - information foundation construction engineering”, Tsinghua University Press, 2002, pp. 78.

[2] D.X Jiang, X.L. Yuan, "The university informatization architecture exploration”, Experimental Technology and Management, May. 2011, pp. 7-11.

[3] X.J. Zhai, K.L. Huang, “Thinking from the university business structure to university data architecture", China Education Information, July. 2007, pp. 32-35.

[4] H. Lin and Y.J. Sun, "Application and Challenge of IT service Management to University Informatization", Instrumentation, Measurrment, Circuits and Systems I ,2011,vol. 127, pp.501-507. 